\title{
Immunization against gonadotropin-releasing hormone in dairy cattle: Antibody titers, ovarian function, hormonal levels, and reversibility
}

\author{
L. Balet, ${ }^{*}$ F. Janett,† J. Hüsler,‡ M. Piechotta,§ R. Howard,\# S. Amatayakul-Chantler,\# A. Steiner, ${ }^{*}$ \\ and $\mathrm{G}$. Hirsbrunner*1 \\ ${ }^{*}$ Clinic for Ruminants, Vetsuisse Faculty, University of Berne, CH-3012 Berne, Switzerland \\ †Clinic of Reproductive Medicine, Vetsuisse Faculty University of Zurich, CH-8057 Zurich, Switzerland \\ łInstitut of Mathematical Statistics and Actuarial Science, University of Berne, CH-3012 Berne, Switzerland \\ $\S$ Clinic for Cattle, University of Veterinary Medicine, Hannover, Bischofsholer Damm 15, 30173 Hannover, Germany \\ \#Zoetis, 45 Poplar Road, A-3052 Parkville, Victoria, Australia
}

\begin{abstract}
Suppression of cyclic activity in cattle is often desired in alpine farming and for feedlot cattle not intended for breeding. A cattle-specific anti-GnRH vaccination (Bopriva, Zoetis Australia Ltd., West Ryde, Australia) is approved for use in heifers and bulls in New Zealand, Australia, Mexico, Brazil, Argentina, Turkey, and Peru. Eleven healthy, cyclic Swiss Fleckvieh cows were included in the study and vaccinated twice with Bopriva 4 wk apart. Injection site, rectal body temperature, and heart and respiratory rates were recorded before and 3 $\mathrm{d}$ following each vaccination. Blood samples were taken weekly for progesterone and estrogen analysis and to determine GnRH antibody titer. Ovaries were examined weekly, using ultrasound to count the number of follicles and identify the presence of a corpus luteum. Thirty weeks after the first vaccination, the cows were subjected to a controlled internal drug-releasing devicebased Select-Synch treatment. The GnRH antibody titers increased after the second vaccination and peaked 2 wk later. Estrogen levels were not influenced by vaccination, and progesterone level decreased in 7 of 11 cows up to 3 wk after the second vaccination and remained low for 10 to $15 \mathrm{wk}$ following the second vaccination. The number of class I follicles (diameter $\leq 5 \mathrm{~mm}$ ) was not influenced by vaccination, whereas the number of class II follicles (diameter 6-9 $\mathrm{mm}$ ) decreased between 7 and 16 wk after the first vaccination. Class III follicles (diameter $>9 \mathrm{~mm}$ ) were totally absent during this period in most cows. The median period until recurrence of class III follicles was $78 \mathrm{~d}$ from the day of the second vaccination (95\% confidence interval: 60-92 d). After vaccination, all cows showed swelling and pain at the injection site, and these reactions subsided within 2
\end{abstract}

Received October 14, 2013.

Accepted January 6, 2014.

${ }^{1}$ Corresponding author: gaby.hirsbrunner@vetsuisse.unibe.ch wk. Body temperature and heart and respiratory rates increased after the first and second vaccinations and returned to normal values within $2 \mathrm{~d}$ of each vaccination. The cows in our study were not observed to display estrus behavior until $30 \mathrm{wk}$ after the first vaccination. Therefore, a Select-Synch protocol was initiated at that time. Ten cows became pregnant after the first insemination (the remaining cow was reinseminated once until confirmed pregnancy). Bopriva induced a reliable and reversible suppression of reproductive cyclicity for more than 2 mo. The best practical predictor for the length of the anestrus period was the absence of class III follicles.

Key words: anti-gonadotropin releasing hormone (anti-GnRH), gonadotropin releasing hormone (GnRH), immunization, antibody titer, anestrus

\section{INTRODUCTION}

Estrus inhibition is frequently requested by livestock owners. Preventing recurrent estrus is desired for alpine farming and for feedlot cattle not intended for breeding. These cows, when untreated, cause disturbance in the herd during estrus and, additionally, are often pregnant at slaughter. In contrast to surgical methods (ovariectomy; Hobson and Hansel, 1972; Bleul et al., 2005), mechanical contraception methods (foreign objects in the uterus; Turin et al., 1997), or permanent administration of progesterone derivatives (Burns et al., 1993; Jacobsen et al., 1995; Denicola et al., 1997; Petta et al., 1998), immunological techniques represent an animal-friendly method for controlling populations (Miller et al., 2000; Curtis et al., 2002). Immunization against GnRH has been used to suppress sexual behavior and to prevent the development of secondary sexual characteristics in males (Finnerty et al., 1998; Cook et al., 2000; Thompson, 2000; D'Occhio et al., 2001; Aïssat et al., 2002; Janett et al., 2003, 2009b, 2012a; Turkstra et al., 2005; Theubet et al., 2010) as 
well as in females (Dalin et al., 2002; Imboden et al., 2006; Elhay et al., 2007; Janett et al., 2009a). In heifers, administration of a human chorionic gonadotropin or LH vaccine (Johnson et al., 1988), as well as a GnRH vaccine (Johnson et al., 1988; Adams and Adams, 1990; Prendiville et al., 1995; Bell et al., 1997; Stevens et al., 2005), has been tested. It could be demonstrated that antibody titers, ovarian function, progesterone concentration, and uterus weight differed significantly after immunization with a recombinant $\mathrm{GnRH}$ antigen from nonimmunized heifers (Geary et al., 2006). Note that these studies all used different presentations of the $\mathrm{GnRH}$ antigen as well as different adjuvants. Immunization with $\mathrm{GnRH}$ prevented the growth of follicles $>5 \mathrm{~mm}$ in diameter and induced anestrus. However, as in mature mares (Dalin et al., 2002; Imboden et al., 2006), the effect of the vaccine varied individually in terms of duration and behavior (Prendiville et al., 1995; Crowe et al., 2001). No information is available in the literature regarding reversibility to estrus in cows after vaccination against $\mathrm{GnRH}$.

The aim of the present study was to evaluate the effect of an active immunization against GnRH (Bopriva, Zoetis Australia Limited, West Ryde, Australia) on $\mathrm{GnRH}$ antibody titer, plasma progesterone and estrogen concentrations, and ovarian activity. Of particular interest were the duration and reversibility of the vaccination-induced anestrus. We hypothesized that the vaccine would increase $\mathrm{GnRH}$ antibody titer, decrease the plasma concentrations of progesterone and estrogen, and reduce the number of follicles $>5 \mathrm{~mm}$ in diameter and therefore induce a phase of anestrus of unknown length. Once pregnancy was confirmed, cows were terminated from the study.

\section{MATERIALS AND METHODS}

\section{Animals and Inclusion and Exclusion Criteria}

Eleven lactating Swiss Fleckvieh cows (cows A through M), from second to sixth lactation (median $=$ third lactation) and 88 to $201 \mathrm{~d}$ postpartum (median $=137 \mathrm{~d}$ ) were included in the study. Inclusion criteria were regular cyclicity before first treatment and uterine health. A uterine swab was taken in diestrus for microbiological and cytological analysis. Results of microbiological samples had to be negative on bacterial culture, and less than 5\% neutrophils (as a proportion of total cells) had to be counted to demonstrate uterine health, according to Gilbert et al. (2005). Exclusion criteria were a history of preceding dystocia or caesarian section, acute or chronic endometritis, cystic ovarian disease, or general diseases (e.g., chronic mastitis, claw diseases).

\section{Animal Care and Housing}

The cows were housed in tie-stalls on straw bedding. From May to October, the cows had daily access to pasture. During winter months, they had access to a courtyard 3 times a week. They were fed an individually calculated ratio of hay and concentrate determined on the basis of individual milk yield, had free access to water, and were milked twice daily.

\section{Treatment with GnRH Vaccine}

The treatment consisted of 2 vaccinations (initial and booster) with the anti-GnRH vaccine Bopriva (Zoetis Australia Ltd.) 4 wk apart (d 0 and 30). Bopriva contains an analog of GnRH linked to a carrier protein combined with a synthetic aqueous adjuvant $(400 \mu \mathrm{g}$ of $\mathrm{GnRH}$-protein-conjugate per $\mathrm{mL}$ ) and is registered with claims to suppress testosterone blood levels in postpubertal bulls and estrus behavior in postpubertal heifers. The dosage used for both the initial and the booster vaccination was $400 \mu \mathrm{g}$ of $\mathrm{GnRH}$-protein-conjugate (1 $\mathrm{mL}$ of Bopriva). All injections were administered subcutaneously on the right side of the neck.

All animal experimentation was performed with permission and in accordance with Swiss law (Nr. BE 29/11).

\section{Clinical Evaluation and Side Effects}

Clinical evaluation included the parameters of body temperature, heart and respiratory rates, and daily milk production. The injection site was meticulously inspected for signs of tissue reaction. Cows were examined directly before each vaccination (d 0) and daily on the following $3 \mathrm{~d}$ or until all parameters examined had returned to normal. Estrus behavior observation was conducted daily after feeding on pasture or in the courtyard.

\section{Blood Sampling, GnRH Antibody Titer, and Hormones}

In all animals, blood was sampled weekly starting 3 wk before vaccination until pregnancy was confirmed. The blood samples were collected by venipuncture from the coccygeal vein into heparinized tubes and centrifuged $(4,000 \times g, 10 \mathrm{~min})$, and plasma was then stored at $-18^{\circ} \mathrm{C}$ for later analysis.

GnRH Antibody Titers. Antibody titers of GnRH were determined by dissociation-enhanced lanthanide fluorescence immunoassay (DELFIA; PerkinElmer Pty Ltd., Glen Waverly, Australia) and results were expressed as relative light units (RLU). Briefly, 384-well, 
streptavidin-coated plates (PerkinElmer Pty Ltd.) were coated for $1 \mathrm{~h}$ at room temperature with $1 \mu \mathrm{g} / \mathrm{mL}$ of biotinylated modified GnRH peptide in DELFIA buffer $(50 \mathrm{~m} M$ Tris- $\mathrm{HCl}, 0.9 \% \mathrm{NaCl}, 0.05 \%$ Tween 20,20 $\mu M$ EDTA, $0.2 \%$ ovalbumin). Plates were washed and then incubated for $1 \mathrm{~h}$ at room temperature with $50-\mu \mathrm{L}$ aliquots of cattle samples serially diluted to 1:800 in DELFIA buffer. Unbound plasma and antibodies were removed by washing, and bound antibody was detected by incubating plates for a further $1 \mathrm{~h}$ with $50 \mu \mathrm{L}$ of europium-labeled protein G (PerkinElmer Pty Ltd.). After washing off excess europium-labeled protein G, DELFIA Enhancement Solution (PerkinElmer Pty Ltd.) was added to all wells to dissociate bound lanthanide from the antigen, forming a highly fluorescent chelate. After $10 \mathrm{~min}$, the intensity of fluorescence was measured by excitation at $340 \mathrm{~nm}$ and emission readings at $615 \mathrm{~nm}$ using a time-resolved fluorometer (Envision 2102 Multireader, PerkinElmer Pty Ltd.). Pooled nonvaccinated cattle samples served as a negative control. Unknown samples were compared with serial dilutions of a standard positive reference immune cattle sample. Calculation of a standard curve and reading of unknown samples were performed using the WorkOut 2.5 software (Dazdaq Solutions Ltd., East Sussex, UK). Intra- and interassay coefficients of variation $(\mathbf{C V})$ were 6.7 and $8.5 \%$, respectively. Serology titers showed a 120-fold range from 3,850 RLU for negative samples to 495,000 titers units for immune samples, with 11,500 RLU being taken as the lower cut-off differentiating positive from negative samples. The lowest detection level of GnRH antibody titer was 3,850 RLU.

Hormone Analysis. Progesterone concentration was measured using RIA (Immunotech, Beckman Coulter, Sinsheim, Germany). The intraassay CV was 5.3\% and the interassay CV was $7.7 \%$, determined by using a bovine serum pool measured 30 times within a test routine and within 25 assay runs. The analytical sensitivity was $0.05 \mathrm{ng} / \mathrm{mL}$ and the measurement range was 0.05 to $50 \mathrm{ng} / \mathrm{mL}$. The assay was performed according to the manufacturer's instructions. Total estrogen concentration was measured after cleavage of glucoronidated and sulfated estrogen by using $0.2 \% \beta$-glucoronidaseacrylsulfatase (Merck, Darmstadt, Germany) for 2 $\mathrm{h}$ at $37^{\circ} \mathrm{C}$ in sodium actetate buffer (Sigma Aldrich, $\mathrm{pH}$ 4.8). Then, steroid hormones were extracted from plasma $(300 \mu \mathrm{L})$ by adding $3 \mathrm{~mL}$ of ether $(30 \% \mathrm{bu}-$ tylmethylether, $70 \%$ benzene). Then, a direct enzymeimmunoassay on microtiter plates using a secondary antibody-coating technique and horseradish peroxidase as the enzyme label were used to measure total estrogen concentration. The enzyme-immunoassay was previously described by Meyer et al. (1990) and Prakash et al. (1987). The used antiserum was raised against 17-estradiol hemisuccinate, and 17-estradiol hemisuccinate horseradish peroxidase was used as steroid-enzyme conjugate (purchased from Technical University of Munich, Freising-Weihenstephan, Germany). The intra- and interassay CV were calculated by repeated measurements of bovine plasma samples. The minimal detectable concentration was $8 \mathrm{pg} / \mathrm{mL}$. The recovery was 84.6 to $96.2 \%$, the intraassay $\mathrm{CV}$ was $8.5 \%$ and the interassay CV was $17.4 \%$.

\section{Gynecological Examination, Insemination, and Pregnancy}

The cows were examined weekly by rectal palpation until they were inseminated. Using ultrasonography (Aquila Pro Vet, Esaote Piemedical, Köln, Germany), the number of follicles was recorded and assigned to 1 of 3 categories, according to the classification of Moreira et al. (2000): class I follicles ( $\leq 5 \mathrm{~mm}$ in diameter), class II follicles (6-9 $\mathrm{mm}$ in diameter), and class III follicles ( $>9 \mathrm{~mm}$ and $<2 \mathrm{~cm}$ in diameter) (Vanholder et al., 2006). The presence of a corpus luteum (CL) was also noted. Thirty weeks after the first vaccination, all cows were treated with a Select-Synch protocol and inseminated. The Select-Synch protocol started with an injection of $20 \mu \mathrm{g}$ of buserelin i.m. (Receptal, MSD Animal Health GmbH, Lucerne, Switzerland) and an intravaginal progesterone-releasing device containing $1.9 \mathrm{~g}$ of progesterone (Eazi-Breed CIDR B, Zoetis, Zurich, Switzerland). Six days later, the cows were injected with $500 \mu \mathrm{g}$ of cloprostenol i.m. (Estrumate, MSD Animal Health $\mathrm{GmbH}$ ), and the CIDR was removed the next day. Cows were inseminated 48 and 72 $\mathrm{h}$ after CIDR removal and received $20 \mu \mathrm{g}$ of buserelin i.m. with the first insemination. Pregnancy diagnosis was performed $35 \mathrm{~d}$ after the first insemination. Cows not pregnant were further treated individually. Cows with confirmed pregnancies were slaughtered.

\section{Statistical Analysis}

Metric variables were described with means, medians, standard deviations, and ranges. Categorical data were analyzed by using contingency tables. We applied nonparametric methods, as the rank correlation coefficient for the relationship of variables that were at least ordinal, and nonparametric confidence intervals. The cow was the statistical independent unit; we observed dependent data within each cow. Because the number of cows was small, we could not apply simple statistical methods, and more sophisticated methods were not appropriate. Hence, $P$-values (e.g., of the rank correlation or $\chi^{2}$ test of the contingency tables) should be interpreted only as an explorative indication. Only 


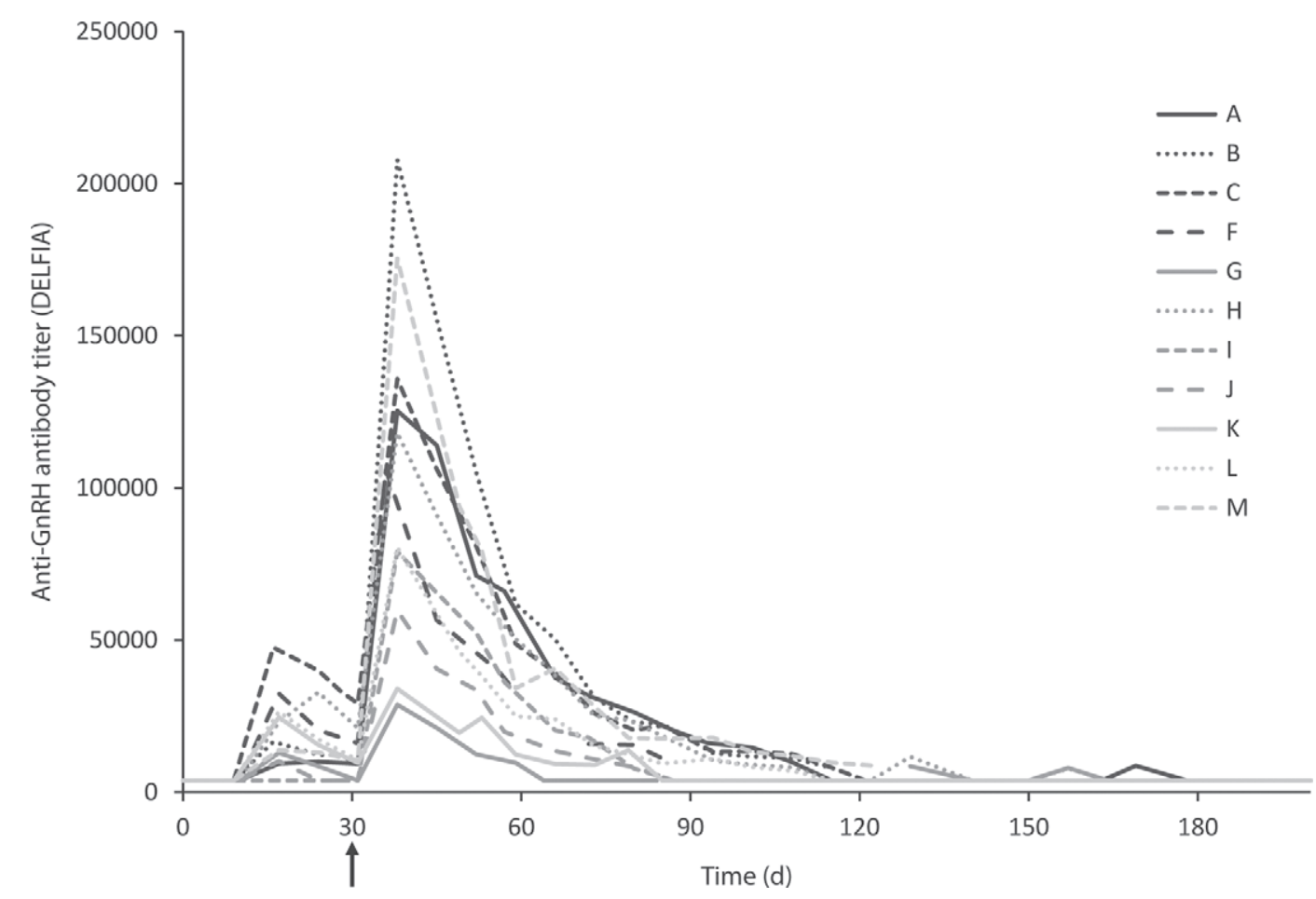

Figure 1. Gonadotropin-releasing hormone antibody titers of 11 cows (A through $\mathrm{M}$ ) after 2 vaccinations (d 0 and d 30, arrow) with antiGnRH vaccine (Bopriva, Zoetis Australia Ltd., West Ryde, Australia). Peak values are shown 6 wk after the first vaccination. DELFIA = dissociation-enhanced lanthanide fluorescence immunoassay.

when the cow was used as statistical unit were the $P$ values of test and nonparametric confidence intervals appropriate and exact. We used SAS software (SAS Institute Inc., Cary, NC) and Statxact software (Cytel Inc., Cambridge, MA) for the statistical analyses.

\section{RESULTS}

\section{GnRH Antibody Titers}

Antibody titers began to increase 2 to 3 wk after the first vaccination but increased significantly after the second vaccination and reached peak values at approximately $6 \mathrm{wk}$ after the first vaccination (Figure 1). Titers decreased to basal values approximately 12 to 17 wk after the first vaccination in all cows. In 7 of 11 cows, the titers remained at basal levels for the rest of the study. In 4 cows, titers increased slightly from basal values at wk 18 and 22 (cows $\mathrm{G}$ and $\mathrm{H}$, respectively) and at wh 24 and 25 (cows A and F, respectively). The GnRH antibody levels were below the detection limit at the time of insemination in all cows. A large variation in the maximum titer was seen in individual vaccinated cows, ranging between 21,174 units (cow G) and 207,830 units (cow B). A titer exceeding 3,850 units (detection limit) was found from $17 \mathrm{~d}$ (95\% CI:
16.5-17) to 97.5 d (95\% CI: 83-111.5) after the first vaccination.

\section{Plasma Progesterone and Estrogen Concentration}

The maximal plasma progesterone concentration measured during the entire study was $49 \mathrm{ng} / \mathrm{mL}$ and the minimal value was $0.1 \mathrm{ng} / \mathrm{mL}$ (Figure 2). The maximal plasma total estrogen concentration measured during the study was $102.0 \mathrm{pg} / \mathrm{mL}$ and the minimal value was the detection limit of $8 \mathrm{pg} / \mathrm{mL}$.

At the time of the first vaccination, 6 cows (A, B, $\mathrm{F}, \mathrm{G}, \mathrm{L}, \mathrm{M})$ showed plasma progesterone concentrations $>3 \mathrm{ng} / \mathrm{mL}, 4$ cows $(\mathrm{H}, \mathrm{I}, \mathrm{J}, \mathrm{K})$ had values $<1$ $\mathrm{ng} / \mathrm{mL}$, and cow $\mathrm{C}$ had a concentration of $1.8 \mathrm{ng} /$ $\mathrm{mL}$. The individual plasma progesterone level fluctuated greatly in the first weeks after vaccination. In 7 cows (A, B, C, G, H, K, M), plasma progesterone decreased to a basal level 3 to 7 wk after the first vaccination (i.e., up to $3 \mathrm{wk}$ after the booster) until wk 14 to 19. After this time, an increase in plasma progesterone concentration was apparent in 6 cows (A, C, G, H, K, M). One cow (F) showed an increase in plasma progesterone concentration from wk 5 that remained high until wk 16. Cows I and J showed a plasma progesterone concentration $>5 \mathrm{ng} / \mathrm{mL}$ in wk 


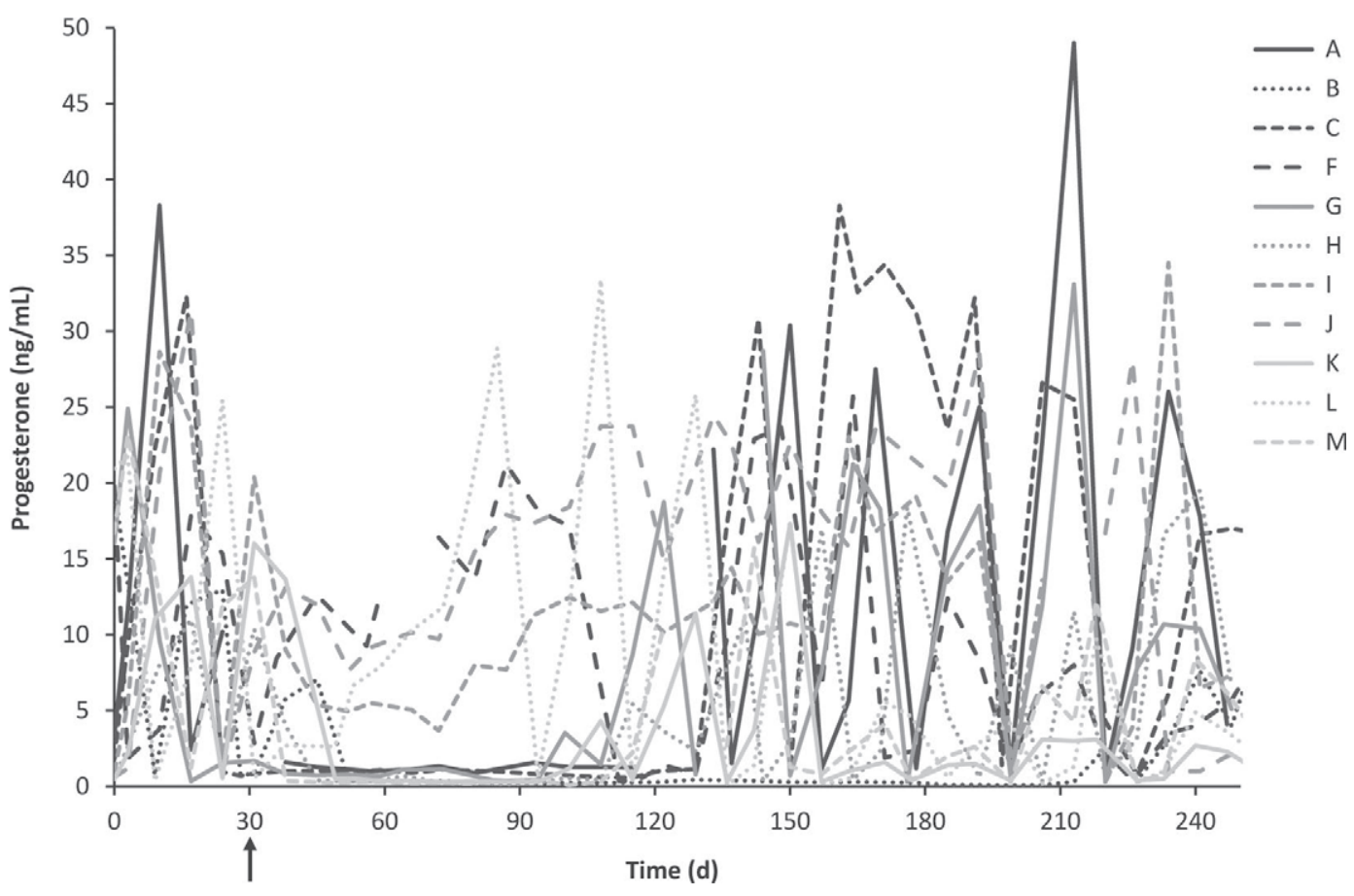

Figure 2. Plasma progesterone values of 11 cows (A through M) after 2 vaccinations (d 0 and d 30, arrow) with anti-GnRH vaccine (Bopriva, Zoetis Australia Ltd., West Ryde, Australia).

5, which increased above 10 and $15 \mathrm{ng} / \mathrm{mL}$ until wk 28 and 17 , respectively. The plasma progesterone level of cow I returned to a fluctuating pattern after wk 28 . In cow J, progesterone levels between 15 and $25 \mathrm{ng} / \mathrm{mL}$ were measured during wk 17 and 28 . Cow L showed a continuous increase of the plasma progesterone level from wk 5 to 12 and reached a peak value of $28.9 \mathrm{ng} /$ $\mathrm{mL}$. The level of plasma progesterone concentration was positively correlated with the presence of a CL (Spearman $\mathrm{r}=0.75 ; P<0.0001$ ).

Seven cows (A, B, C, F, H, I, J) showed fluctuating values of total plasma estrogen concentration during the study (data not shown), with peak values of 33.1 to $58.3 \mathrm{pg} / \mathrm{mL}$, and minimal values below the detection limit. Cows K, L, and M showed fluctuating values until wk 11 after the first vaccination and then the values decreased below the detection limit until insemination, except for a very slight increase for cows $L$ and $M$ in wk 15 and 19, respectively. Cow G showed fluctuating values of total plasma estrogen concentration throughout the study, with very high peak values $(102.0 \mathrm{pg} /$ $\mathrm{mL}$ at wk 13).

\section{Ovarian Ultrasonography}

The number of class I follicles did not vary for $30 \mathrm{wk}$ after the first immunization (Figure 3), whereas the number of class II follicles decreased between wk 7 and
17 , although they were still present in some cows. Class III follicles were completely absent from wk 7 ( $\pm 2 \mathrm{wk}$ ) to wk $16( \pm 3 \mathrm{wk})$ after the first vaccination (i.e., 3 wk after the booster) in all the cows except for cow G (Figure $4 \mathrm{a}, \mathrm{b}$ ).

At the time of the first vaccination, a CL was present in $70 \%(8 / 11)$ of the cows. Four of the 11 cows developed a persistent CL over a maximum of $166 \mathrm{~d}$ after the second vaccination.

Figure 5 illustrates the correlation between GnRH antibody titers (d 17-97.5) and number of class III follicles; fewer class III follicles were present when $\mathrm{GnRH}$ antibody titers were high $(P<0.0001$; phi coefficient $=-0.461)$.

\section{Pregnancy Diagnosis}

Ten of 11 cows were confirmed pregnant $35 \mathrm{~d}$ after insemination following the Select-Synch protocol; $1 \mathrm{cow}$ $(\mathrm{J})$ was not pregnant at this time. In cow J, a CL on the right ovary and some class II follicles on both ovaries were observed, and the uterus showed no pathological findings. The cow was injected with $500 \mu \mathrm{g}$ of cloprostenol i.m. (Estrumate, MSD Animal Health GmbH) on d 39 postinsemination and with $20 \mu \mathrm{g}$ of buserelin i.m. (Receptal, MSD Animal Health GmbH) on d 41. Inseminations were performed on d 41 and 42 and she was confirmed pregnant 35 d later. 


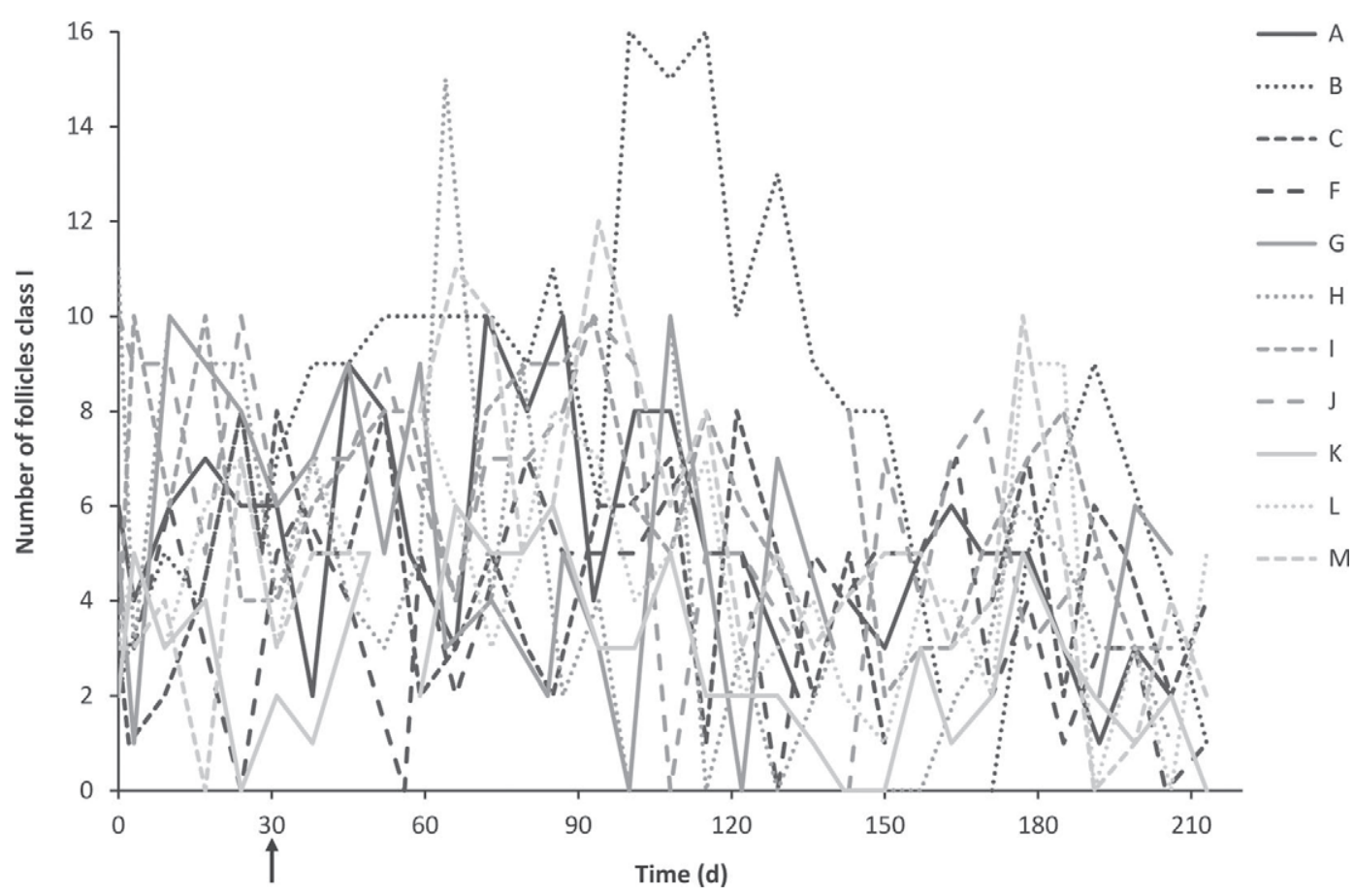

Figure 3. Number of class I follicles of 11 cows (A through M) after 2 vaccinations (d 0 and d 30, arrow) with anti-GnRH vaccine (Bopriva, Zoetis Australia Ltd., West Ryde, Australia).

\section{Clinical Evaluation and Adverse Effects}

No estrus behavior was observed in the GnRH-vaccinated cows even after anti-GnRH titers reached basal values and although class III follicles and the presence of a CL on the ovaries indicated resumption of reproductive cyclicity.

All cows treated with Bopriva showed a swelling at the injection site (varying in severity) and moderate to substantial local pain. In all animals, the local reactions subsided within 2 to 4 wk. A transient increase in rectal body temperature was apparent $24 \mathrm{~h}$ after the first (median; $25 \%$ and $75 \%$ quartiles: $39.2^{\circ} \mathrm{C} ; 39.1^{\circ} \mathrm{C}, 40.3^{\circ} \mathrm{C}$ ) and the second vaccination $\left(39.5^{\circ} \mathrm{C} ; 38.8^{\circ} \mathrm{C}, 40.4^{\circ} \mathrm{C}\right.$; Table 1). Heart rate (beats per min) increased after the first $(88 ; 84,100)$ and the second $(88 ; 80,90)$ vaccinations and returned to normal within $48 \mathrm{~h}$ after vaccination. Respiratory rate (breaths/min) increased after the first $(34 ; 36,56)$ and the second $(32 ; 40,48)$ vaccinations and returned to normal within $48 \mathrm{~h}$ postvaccination. No signs of apathy, reduced food intake, or decrease in milk production were observed. In 1 cow $(\mathrm{J})$, a hydrometra was diagnosed 28 wk after the first vaccination and was successfully treated with $500 \mu \mathrm{g}$ of cloprostenol i.m. (Estrumate, MSD Animal Health GmbH).

\section{DISCUSSION}

All cows showed similar patterns of GnRH antibody production after immunization, with a rapid onset of immune response and a peak 2 to 3 wk after the second vaccination. However, the maximal values of individual anti-GnRH antibodies varied greatly, due to the multistep involvements required for the immune system to establish antibodies to exposed antigens, as well as the individual variation in terms of the condition of the animals, their nutritional state, and a strong genetic component for major histocompatibility complex (Fluri et al., 2006).

Antibody titers $>3,850$ (detection limit) were found between 17 and $97.5 \mathrm{~d}$ after the first vaccination. This duration of effect is consistent with results in pubertal bull calves (Theubet et al., 2010; Janett et al., 2012a) but shorter than that observed in prepubertal bull calves (Janett et al., 2012b). The longer duration seen in prepubertal bull calves is most likely due to the vaccine resulting in a delay in the onset of puberty.

As expected, the number of class I follicles was not influenced by vaccination. Class I follicles in cattle are independent of gonadotropin (Campbell et al., 1995). The number of class II follicles was partly reduced, but class II follicles did not completely disappear after the second vaccination. In heifers, follicles with a diameter $>5 \mathrm{~mm}$ are suppressed after vaccination against $\mathrm{GnRH}$ (Prendiville et al., 1995; Crowe et al., 2001). In our study, class III follicles were completely absent in 10 of 11 cows between 7 and 16 wk following 2 vaccinations of Bopriva. Cow $\mathrm{G}$ exhibited a low immune response to Bopriva as reflected in low GnRH antibody titers 


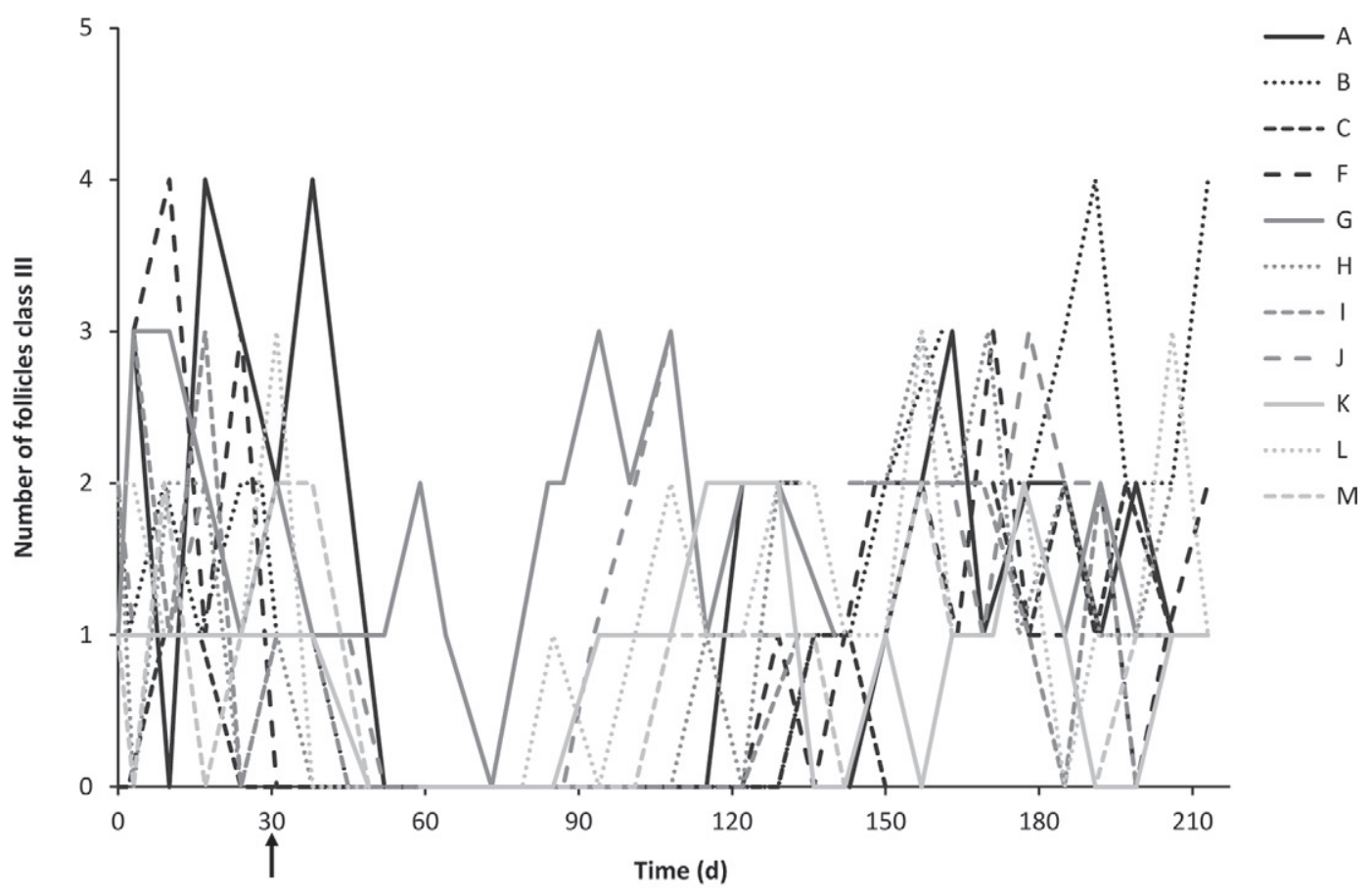

(a)

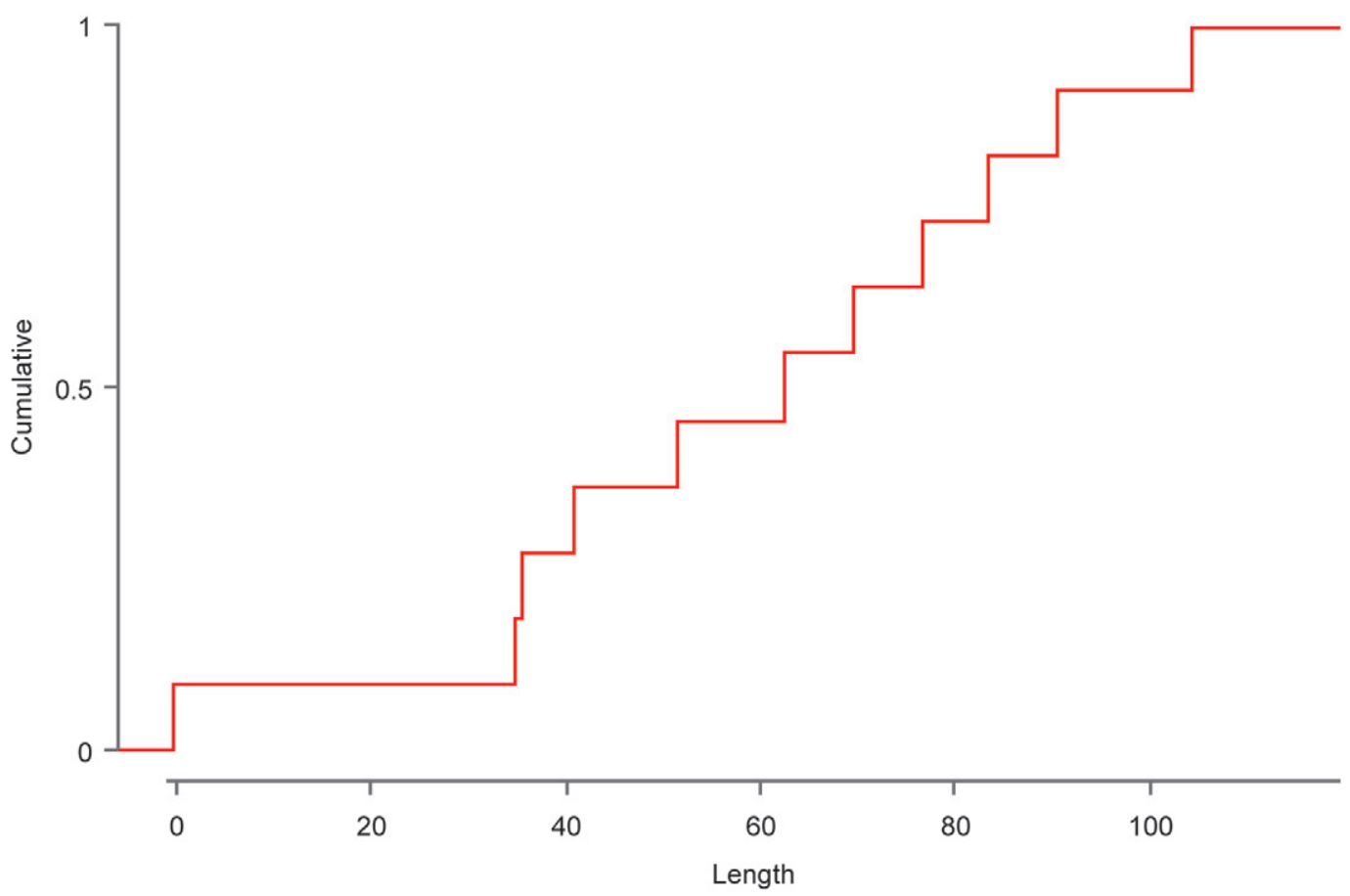

(b)

Figure 4. (a) Number of class III follicles of 11 cows (A through $\mathrm{M}$ ) after 2 vaccinations (d 0 and d 30, arrow) with anti-GnRH vaccine (Bopriva, Zoetis Australia Ltd., West Ryde, Australia). These follicles were completely absent from wk 7 ( $\pm 2 \mathrm{wk}$ ) to wk 16 ( $\pm 3 \mathrm{wk}$ ) for all the cows except for cow G. (b) Survival analysis of class III follicles (empirical distribution, function of length in days of absence of class III follicles until class III follicles are present again). Color version available in the online PDF. 
BALET ET AL.

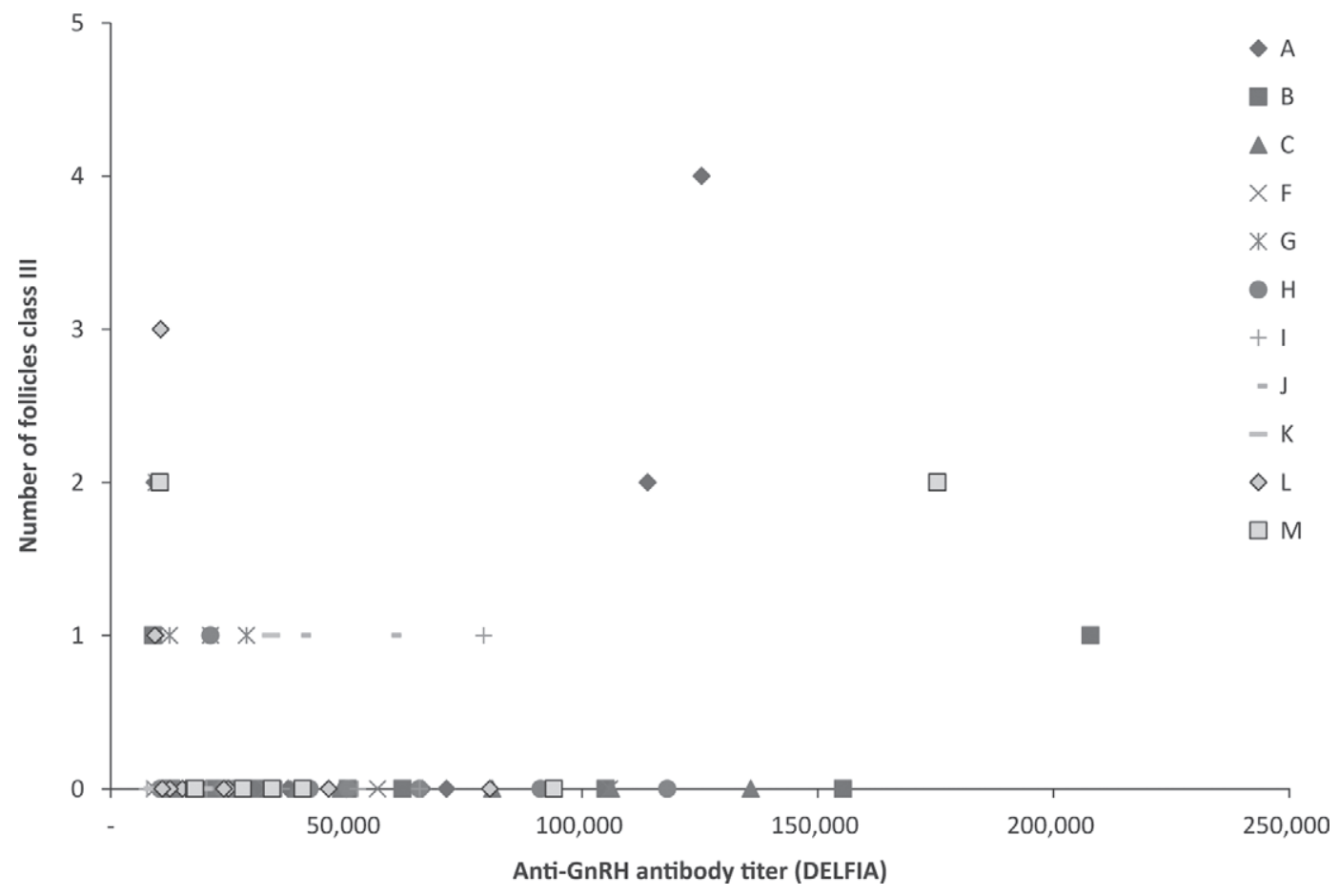

Figure 5. Association of class III follicles with GnRH antibody titer. DELFIA = dissociation-enhanced lanthanide fluorescence immunoassay.

Table 1. Temperature, heart rate, and respiration before vaccination $(\mathrm{d} 0)$ and on the $3 \mathrm{~d}$ following the first vaccination (1) with anti-GnRH vaccine (Bopriva, Zoetis Australia Ltd., West Ryde, Australia) and the second vaccination $(2)$

\begin{tabular}{|c|c|c|c|}
\hline Trait & $25 \%$ quartile & Median & $75 \%$ quartile \\
\hline \multicolumn{4}{|c|}{ Temperature $\left({ }^{\circ} \mathrm{C}\right)$} \\
\hline d $0(1)$ & 38.1 & 38.4 & 38.4 \\
\hline d 1 (1) & 39.1 & 39.2 & 40.3 \\
\hline d $2(1)$ & 38.2 & 38.4 & 38.6 \\
\hline d $3(1)$ & 38.1 & 38.5 & 38.7 \\
\hline d $0(2)$ & 38.5 & 38.6 & 38.8 \\
\hline d 1 (2) & 38.8 & 39.5 & 40.4 \\
\hline d $2(2)$ & 38.1 & 38.7 & 38.8 \\
\hline d $3(2)$ & 38.1 & 38.3 & 38.5 \\
\hline \multicolumn{4}{|c|}{ Heart rate (beats/min) } \\
\hline d 0 (1) & 68 & 80 & 84 \\
\hline d 1 (1) & 84 & 88 & 100 \\
\hline d $2(1)$ & 73 & 80 & 85 \\
\hline d 3 (1) & 68 & 80 & 88 \\
\hline d $0(2)$ & 72 & 84 & 90 \\
\hline d 1 (2) & 80 & 88 & 90 \\
\hline d $2(2)$ & 80 & 84 & 90 \\
\hline d $3(2)$ & 74 & 80 & 84 \\
\hline \multicolumn{4}{|c|}{ Respiratory rate (breaths/min) } \\
\hline d 0 (1) & 30 & 32 & 36 \\
\hline d 1 (1) & 36 & 44 & 56 \\
\hline d $2(1)$ & 32 & 38 & 46 \\
\hline d $3(1)$ & 36 & 40 & 46 \\
\hline d $0(2)$ & 24 & 36 & 44 \\
\hline d 1 (2) & 32 & 40 & 48 \\
\hline d $2(2)$ & 30 & 32 & 52 \\
\hline d $3(2)$ & 28 & 35 & 42 \\
\hline
\end{tabular}


and, subsequently, large follicle development was not suppressed. Earlier studies in cattle suggest that recruitment of follicles is likely to be FSH-dependent and that selection and growth of follicles above 7 to $9 \mathrm{~mm}$ in diameter is LH-dependent (Gong et al., 1996; Bao et al., 1997).

Plasma progesterone (e.g., estrus values vs. diestrus values) at the time of the first vaccination did not affect later values of plasma progesterone concentration during the study. Despite the production of GnRH antibodies, 4 cows showed a CL and a plasma progesterone concentration $>1 \mathrm{ng} / \mathrm{mL}$. Earlier studies in heifers and ewes (Hixon et al., 1975; Hughes et al., 1987) suggested that estradiol production from follicles could play a role in luteolysis; therefore, the suppression of follicle development could prolong the lifespan of a CL (Okuda et al., 2002). The lack of class III follicles might explain why no luteolysis occurred in some cows. In our study, the total plasma estrogen concentration was not affected by the production of GnRH antibodies. A good correlation exists between total estrogen and estradiol-17 $\beta$ (Mondal et al., 2006). Other studies in mares (Dalin et al., 2002; Imboden et al., 2006) and heifers (Prendiville et al., 1995) described a reduced estradiol-17 $\beta$ level after GnRH vaccination. Dalin et al. (2002) indicated that in mares, the estrus cycle stage at first immunization might have an influence on hormonal levels. Furthermore, in the study of Dalin et al. (2002), ovarian atrophy in mares did not correlate with cycle blockade. Among all parameters evaluated in our study, the suppression of class III follicles was the most reliable and easily detectable parameter for clinicians to predict the efficiency of the vaccine. Large follicles are almost always present in healthy cyclic cows because follicle growth occurs in waves (Lucy et al., 1992). In this study, the class III follicles were absent from wk 7 to 16 after the primary vaccination and cows entered anestrus approximately 3 wk after the booster injection. An important finding of the current study was that the immunization against $\mathrm{GnRH}$ was entirely reversible as shown by the return to basal levels of the GnRH antibody titer and with successful insemination of all the cows. These results confirm that Bopriva can be used in a safe manner in cows, as already seen in bull calves (Theubet et al., 2010; Janett et al., 2012a,b). In our study, the general condition and milk yield of cows were not disturbed by the vaccine, despite a short-term increase in rectal body temperature and a local reaction at the site of vaccination (data not shown). One noteworthy adverse effect was the hydrometra developed by cow J. This was the only cow needing 2 inseminations to become pregnant. The authors did not find any other case of hydrometra published in conjunction with the use of GnRH immunization. It is unclear whether it occurred causally or as a coincidence.

In addition to seasonal breeding systems, temporary immunization against GnRH could be used in seasonal alpine pasturing systems. Cows not pregnant during the seasonal alpine pasturing disturb the herd because of recurring estrus behavior. This is especially accentuated in the Swiss Hérens breed, which is raised for fighting and selected for dominance abilities (Plusquellec and Bouissou, 2001). Suppression of estrus during alpine pasturing is highly valued but, with the exception of intravaginal progesterone devices, currently no pharmaceuticals are permitted in Switzerland for production animals. Immunization against $\mathrm{GnRH}$ could be considered an animal-friendly solution for these cows and producers.

The cows in our study were not observed to be displaying estrus behavior until wk 30, when the SelectSynch protocol was started. In future studies, we plan to evaluate estrus behavior and return to cyclicity of cows in herds that include a bull. Alternatively to using a bull, heat detection patches could be used. Furthermore, a large clinical field study is planned, in which we will evaluate the influence of cycle stage at first and second vaccinations on characteristics of hormones and behavior.

\section{ACKNOWLEDGMENTS}

We thank Zoetis Animal Health (Zurich, Switzerland), MSD Animal Health GmbH (Lucerne, Switzerland), the Fédération d'élevage de la race d'Hérens (Ardon, Switzerland), the Fondation Michellod pour la sauvegarde de la race d'Hérens (Bagnes, Switzerland) for their support.

\section{REFERENCES}

Adams, T. E., and B. M. Adams. 1990. Reproductive function and feedlot performance of beef heifers actively immunized against GnRH. J. Anim. Sci. 68:2793-2802.

Aïssat, D., J. M. Sosa, D. M. de Avila, K. P. Bertrand, and J. J. Reeves. 2002. Endocrine, growth, and carcass characteristics of bulls immunized against luteinizing hormone-releasing hormone fusion proteins. J. Anim. Sci. 80:2209-2213.

Bao, B., H. A. Garverick, G. W. Smith, B. E. Salfen, and R. S. Youngquist. 1997. Changes in messenger ribonucleic acid encoding luteinizing hormone receptor, cytochrome $\mathrm{P} 450$-side chain cleavage, and aromatase are associated with recruitment and selection of bovine ovarian follicles. Biol. Reprod. 56:1158-1168.

Bell, M., C. A. Daley, S. L. Berry, and T. E. Adams. 1997. Pregnancy status and feedlot performance of beef heifers actively immunized against gonadotropin-releasing hormone. J. Anim. Sci. 75:11851189.

Bleul, U., K. Hollenstein, and W. Kähn. 2005. Laparoscopic ovariectomy in standing cows. Anim. Reprod. Sci. 90:193-200.

Burns, P. D., J. C. Spitzer, G. L. Burns, and B. B. Plyler. 1993. Inhibition of estrus and corpora lutea function with Norgestomet. Theriogenology 39:863-873. 
Campbell, B. K., R. J. Scaramuzzi, and R. Webb. 1995. Control of antral follicle development and selection in sheep and cattle. J. Reprod. Fertil. Suppl. 49:335-350.

Cook, R. B., J. D. Popp, J. P. Kastelic, S. Robbins, and R. Harland. 2000. The effects of active immunization against $\mathrm{GnRH}$ on testicular development, feedlot performance, and carcass characteristics of beef bulls. J. Anim. Sci. 78:2778-2783.

Crowe, M. A., P. Kelly, M. A. Driancourt, M. P. Boland, and J. F Roche. 2001. Effects of follicle-stimulating hormone with and without luteinizing hormone on serum hormone concentrations, follicle growth, and intrafollicular estradiol and aromatase activity in gonadotropin-releasing hormone-immunized heifers. Biol. Reprod. 64:368-374.

Curtis, P. D., R. L. Pooler, M. E. Richmond, L. A. Miller, G. F. Mattfeld, and F. W. Quimby. 2002. Comparative effects of GnRH and porcine zona pellucida (PZP) immunocontraceptive vaccines for controlling reproduction in white-tailed deer (Odocoileus virginianus). Reprod. Suppl. 60:131-141.

D'Occhio, M. J., W. J. Aspden, and T. E. Trigg. 2001. Sustained testicular atrophy in bulls actively immunized against $\mathrm{GnRH}$ Potential to control carcass characteristics. Anim. Reprod. Sci. 66:47-58.

Dalin, A. M., O. Andresen, and L. Malmgren. 2002. Immunization against GnRH in mature mares: Antibody titres, ovarian function, hormonal levels and oestrous behaviour. J. Vet. Med. A Physiol. Pathol. Clin. Med. 49:125-131.

Denicola, A., D. Kesler, and R. Swihart. 1997. Dose determination and efficacy of remotely delivered norgestomet implants on contraception of white-tailed deer. Zoo Biol. 16:31-37.

Elhay, M., A. Newbold, A. Britton, P. Turley, K. Dowsett, and J. Walker. 2007. Suppression of behavioural and physiological oestrus in the mare by vaccination against GnRH. Aust. Vet. J. 85:39-45.

Finnerty, M., W. J. Enright, and J. F. Roche. 1998. Testosterone, LH and FSH episodic secretory patterns in GnRH-immunized bulls. J. Reprod. Fertil. 114:85-94

Fluri, A., C. Nenci, M.-L. Zahno, H.-R. Vogt, S. Charan, A. Busato, G. Pancino, E. Peterhans, G. Obexer-Ruff, and G. Bertoni. 2006. The MHC-haplotype influences primary, but not memory, immune responses to an immunodominant peptide containing T- and B-cell epitopes of the caprine arthritis encephalitis virus Gag protein. Vaccine 24:597-606.

Geary, T. W., E. E. Grings, M. D. MacNeil, D. M. de Avila, and J. J. Reeves. 2006. Use of recombinant gonadotropin-releasing hormone antigens for immunosterilization of beef heifers. J. Anim. Sci. 84:343-350.

Gilbert, R. O., S. T. Shin, Ch. L. Guard, H. N. Erb, and M. Frajblat. 2005. Prevalence of endometritis and its effects on reproductive performance of dairy cows. Theriogenology 64:1879-1888.

Gong, J. G., B. K. Campbell, T. A. Bramley, C. G. Gutierrez, A. R. Peters, and R. Webb. 1996. Suppression in the secretion of folliclestimulating hormone and luteinizing hormone, and ovarian follicle development in heifers continuously infused with a gonadotropinreleasing hormone agonist. Biol. Reprod. 55:68-74.

Hixon, J. E., D. R. Gengenbach, and W. Hansel. 1975. Failure of prostaglandin $\mathrm{F}_{2 \alpha}$ to cause luteal regression in ewes after destruction of ovarian follicles by x-irradiation. Biol. Reprod. 13:126-135.

Hobson, W. C., and W. Hansel. 1972. Plasma LH levels after ovariectomy, corpus luteum removal and estradiol administration in cattle. Endocrinology 91:185-190.

Hughes, T. L., A. Villa-Godoy, J. S. Kesner, and R. L. Fogwell. 1987. Destruction of bovine ovarian follicles: Effects on the pulsatile release of luteinizing hormone and prostaglandin $\mathrm{F}_{2 \alpha}$-induced luteal regression. Biol. Reprod. 36:523-529.

Imboden, I., F. Janett, D. Burger, M. A. Crowe, M. Hassig, and R. Thun. 2006. Influence of immunization against $\mathrm{GnRH}$ on reproductive cyclicity and estrous behavior in the mare. Theriogenology $66: 1866-1875$.

Jacobsen, N., D. Jessup, and D. Kesler. 1995. Contraception in captive black-tailed deer by remotely delivered norgestomet ballistic implants. Wildl. Soc. Bull. 23:718-722.
Janett, F., T. Gerig, A. C. Tschuor, S. Amatayakul-Chantler, J. Walker, R. Howard, H. Bollwein, and R. Thun. 2012a. Vaccination against gonadotropin-releasing factor (GnRF) with Bopriva significantly decreases testicular development, serum testosterone levels and physical activity in pubertal bulls. Theriogenology $78: 182-188$.

Janett, F., T. Gerig, A. C. Tschuor, S. Amatayakul-Chantler, J. Walker, R. Howard, M. Piechotta, H. Bollwein, S. Hartnack, and R. Thun. 2012b. Effect of vaccination against gonadotropin-releasing factor $(\mathrm{GnRF})$ with Bopriva ${ }^{\circledR}$ in the prepubertal bull calf. Anim. Reprod. Sci. 131:72-80.

Janett, F., U. Lanker, H. Jorg, M. Hassig, and R. Thun. 2003. [The castration of male lambs by immunization against GnRH]. Schweiz. Arch. Tierheilkd. 145:291-299. [In German]

Janett, F., U. Lanker, H. Jorg, E. Meijerink, and R. Thun. 2009a. [Suppression of reproductive cyclicity by active immunization against GnRH in the adult ewe]. Schweiz. Arch. Tierheilkd. 151:53-59. [In German]

Janett, F., R. Stump, D. Burger, and R. Thun. 2009b. Suppression of testicular function and sexual behavior by vaccination against GnRH (Equity) in the adult stallion. Anim. Reprod. Sci. 115:88102.

Johnson, H. E., D. M. DeAvila, C. F. Chang, and J. J. Reeves. 1988. Active immunization of heifers against luteinizing hormone-releasing hormone, human chorionic gonadotropin and bovine luteinizing hormone. J. Anim. Sci. 66:719-726.

Lucy, M. C.. J. D. Savio, L. Badinga, R. L. De La Sota, and W. W. Thatcher. 1992. Factors that affect ovarian follicular dynamics in cattle. J. Anim. Sci. 70:3615-3626.

Meyer, H. H. D., H. Sauerwein, and B. M. Mutayoba. 1990. Immunoaffinity chromatography and a biotin-streptavidin amplified enzymeimmunoassay for sensitive and specific estimation of estradiol-17- $\beta$. J. Steroid Biochem. Mol. Biol. 35:263-269.

Miller, L. A., B. E. Johns, and G. J. Killian. 2000. Immunocontraception of white-tailed deer with GnRH vaccine. Am. J. Reprod. Immunol. 44:266-274.

Mondal, M., C. Rajkhowa, and B. S. Prakash. 2006. Relationship of plasma estradiol-17 $\beta$, total estrogen, and progesterone to estrus behavior in mithun (Bos frontalis) cows. Horm. Behav. 49:626633.

Moreira, F., R. L. de la Sota, T. Diaz, and W. W. Thatcher. 2000. Effect of day of the estrous cycle at the initiation of a timed artificial insemination protocol on reproductive responses in dairy heifers. J. Anim. Sci. 78:1568-1576.

Okuda, K., Y. Miyamoto, and D. J. Skarzynski. 2002. Regulation of endometrial prostaglandin $\mathrm{F}_{2 \alpha}$ synthesis during luteolysis and early pregnancy in cattle. Domest. Anim. Endocrinol. 23:255-264.

Petta, C. A., A. Faundes, T. R. Dunson, M. Ramos, M. DeLucio, D. Faundes, and L. Bahamondes. 1998. Timing of onset of contraceptive effectiveness in Depo-Provera users: Part I. Changes in cervical mucus. Fertil. Steril. 69:252-257.

Plusquellec, P., and M. Bouissou. 2001. Behavioural characteristics of two dairy breeds of cows selected (Herens) or not (Brune des Alpes) for fighting and dominance ability. Appl. Anim. Behav. Sci. 72:1-21.

Prakash, B. S., H. H. D. Meyer, E. Schallenberger, and D. F. M. Vandewiel. 1987. Development of a sensitive enzyme immunoassay (EIA) for progesterone determination in unextracted bovine plasma using the 2nd antibody technique. J. Steroid Biochem. Mol. Biol. 28:623-627.

Prendiville, D. J., W. J. Enright, M. A. Crowe, M. Finnerty, N. Hynes, and J. F. Roche. 1995. Immunization of heifers against gonadotropin-releasing hormone: Antibody titers, ovarian function, body growth, and carcass characteristics. J. Anim. Sci. 73:2382-2389.

Stevens, J. D., J. M. Sosa, D. M. deAvila, J. M. Oatley, K. P. Bertrand, C. T. Gaskins, and J. J. Reeves. 2005. Luteinizing hormonereleasing hormone fusion protein vaccines block estrous cycle activity in beef heifers. J. Anim. Sci. 83:152-159. 
Theubet, G., R. Thun, M. Hilbe, and F. Janett. 2010. [Effect of vaccination against $\mathrm{GnRH}\left(\right.$ Bopriva $\left.{ }^{\circledR}\right)$ in the male pubertal calf]. Schweiz. Arch. Tierheilkd. 152:459-469. [In German].

Thompson, D. L. 2000. Immunization against GnRH in male species (comparative aspects). Anim. Reprod. Sci. 60-61:459-469.

Turin, E. M., C. A. Nagle, M. Lahoz, M. Torres, M. Turin, A. F. Mendizabal, and M. B. Escofet. 1997. Effects of a copper-bearing intrauterine device on the ovarian function, body weight gain and pregnancy rate of nulliparous heifers. Theriogenology 47:1327-1336.
Turkstra, J. A., F. J. van der Meer, J. Knaap, P. J. Rottier, K. J. Teerds, B. Colenbrander, and R. H. Meloen. 2005. Effects of $\mathrm{GnRH}$ immunization in sexually mature pony stallions. Anim. Reprod. Sci. 86:247-259.

Vanholder, T., G. Opsomer, and A. de Kriuf. 2006. Aetiology and pathogenesis of cystic ovarian follicles in dairy cattle: A review. Reprod. Nutr. Dev. 46:105-119. 